\title{
Are Cognitive Load and Focus of Attention Differentially Involved in Pain Management: An Experimental Study Using a Cold Pressor Test and Virtual Reality
}

This article was published in the following Dove Press journal:

Journal of Pain Research

\author{
Stéphanie Dumoulin' \\ Stéphane Bouchard (D) ${ }^{2-4}$ \\ Claudie Loranger ${ }^{2,4}$ \\ Pamela Quintana ${ }^{2}$ \\ Véronique Gougeon ${ }^{5}$ \\ Kim L Lavoie ${ }^{1,6}$
}

\begin{abstract}
'Department of Psychology, Université du Québec à Montréal, Montréal, QC, Canada; ${ }^{2}$ Cyberpsychology Lab, Université du Québec en Outaouais, Gatineau, QC, Canada; ${ }^{3}$ School of Psychology, University of Ottawa, Ottawa, ON, Canada; ${ }^{4}$ Research Center, Centre Intégré de Santé et de Services Sociaux de l'Outaouais, Gatineau, QC, Canada; ${ }^{5}$ Department of Psychology, Université de Sherbrooke, Sherbrooke, QC, Canada; ${ }^{6}$ Montreal Behavioral Medicine Center, Research Center, CIUSSS-NIM Hôpital du Sacré-Coeur de Montréal, Montréal, QC, Canada
\end{abstract}

Objective: The aim of this study is to assess whether distraction (lack of attentional focus) and attention (cognitive load) are differentially involved in the analgesic effect of virtual reality (VR) immersions during a cold pressor test (CPT).

Methods: Thirty-one participants were randomly assigned to four experimental conditions (high and low cognitive load, attention with or without a reminder of the pain stimuli) and performed three CPTs. Pain was assessed based on the duration of the CPT (pain tolerance), a visual analog rating scale of perceived pain intensity during the CPT and the subjective pain scale of the Short form McGill Pain Questionnaire (SF-MPQ).

Results: The statistical analyses revealed that VR immersions were associated with less pain compared to the baseline (all $\mathrm{p}<0.001$ ), but for the experimental manipulations, only the conditions where there was an increase in cognitive load (ie, from low cognitive load at Immersion 1 to high cognitive load at Immersion 2) were effective for increasing pain tolerance (significant Time X Conditions interaction). The interactions were not significant for pain intensity assessed with the VAS or the SF-MPQ.

Conclusion: The results suggest that increases in cognitive load play an important role in the analgesic effect of VR immersion, although the combination of attentional focus and cognitive load may be important. Suggestions are given for designing a replication study.

Keywords: virtual reality, pain, attention, cognitive load, distraction, cold pressor test, CPT

\section{Introduction}

Pain is a highly subjective phenomenon influenced by a number of psychological and physiological variables. ${ }^{1}$ According to the model proposed by Leventhal et al, ${ }^{2}$ distraction is an effective method for reducing pain. It makes it possible to direct the focus of attention elsewhere than on the emotional or sensory components of a nociceptive perception. ${ }^{3}$

A large range of non-pharmaceutical methods have been found to be effective in reducing pain, from psychological interventions such as cognitive-behavioral therapy, ${ }^{4}$ biofeedback, ${ }^{5}$ guided imagery ${ }^{6,7}$ and hypnosis ${ }^{8}$ to distraction techniques such as listening to music ${ }^{9,10}$ and reading. ${ }^{11}$ Virtual reality (VR) is a relatively new technology that allows patients to immerse themselves in a three-dimensional (3D)generated world. It can be defined as the use of computer and behavioural interfaces to simulate the behaviour of $3 \mathrm{D}$ entities that interact in real time with each other
Correspondence: Stéphane Bouchard Cyberpsychology Lab, Université du Québec en Outaouais, C.P. 1250, Succ. Hull, 283 Boul. Alexandre-Taché, $2^{\mathrm{e}}$ Étage, Local C-2500, Gatineau, Quebec J8X

$3 \times 7$, Canada

Tel + I-819-595-3900 \#2360

$\mathrm{Fax}+1$ 819-595-2250

Email stephane.bouchard@uqo.ca
Journal of Pain Research 2020:13 2213-2222

2213 
and with a user immersed via sensorimotor channels. ${ }^{12}$ The immersion creates the illusion that the user has left the physical environment and is now "present" in the virtual environment. ${ }^{13}$ According to Hines and Martin ${ }^{14}$ and Sylvestre, ${ }^{15}$ VR meets the necessary criteria to be qualified as a distractor. ${ }^{16}$ Indeed, it has the capacity to take attention away from a potentially harmful stimulus and direct it towards a neutral or pleasant stimulus by competing for attentional resources and blocking external stimulation associated with the painful stimuli. ${ }^{16}$ The efficacy of this method may involve several mechanisms in combination with its immersive nature, including diverting attention away from the nociceptive stimulus and increasing the cognitive load by having the individual perform tasks that compete for the attentional resources oriented toward the nociceptive stimulus.

Two literature reviews ${ }^{17,18}$ and a comprehensive listing of the available literature by Sulea et $\mathrm{al}^{19}$ on the use of VR in pain management were conducted. Overall, more than 100 experimental studies where VR distraction was studied were found. Their results indicated that distraction using VR immersion can be effective in reducing different kinds of pain, from painful medical procedures (eg burn patients) ${ }^{20-22}$ dental procedures; ${ }^{23}$ intravenous (IV) placements; ${ }^{24}$ implantation of venous access ports; ${ }^{25,26}$ lumbar punctures; ${ }^{27}$ and physical therapy. ${ }^{28} \mathrm{~A}$ headset that screens out external stimuli and provides visual stimuli combined with an audio distraction seems to be more distractive than visual stimuli alone. ${ }^{29}$ Malloy and Milling ${ }^{18}$ also suggested that the use of more sophisticated VR technology allowing for the full immersion of individuals in a virtual environment was associated with greater pain reduction. When examining the results of studies included in the two reviews on VR, ${ }^{17,18}$ two factors seem to emerge as potential mechanisms in VR distraction: (a) changing the focus of attention and (b) increasing the cognitive load to allow less attentional resources to attend to nociceptive stimuli. Indeed, distraction is a complex phenomenon involving a process by which an individual diverts his attention away from nociceptive stimuli towards any strategy aiming to block awareness of the stimuli or their effects ${ }^{14,15,30,31}$ to help cope with the pain. $^{32}$ It allows the individual to actively engage in a task or a cognitive and/or behavioural activity.

According to Melzack and Wall, ${ }^{33}$ any task or activity with the potential to divert the focus of attention away from the pain and to act as a distractor has the potential to inhibit pain. When managing sudden painful stimuli, an individual's attention will go to the source or location of the harmful stimulation, causing a decrease or complete cessation of the current task. ${ }^{34}$ The pain becomes the main focus, being the top attention-grabbing stimulus of all environmental and internal stimuli. Since pain is a warning sign of danger to the organism, it interrupts, distracts, and demands attention. ${ }^{35}$ Several researchers agree that the diversion of attention towards a stimulus other than the pain itself could have the effect of reducing the subjective experience of pain in terms of intensity and feelings of discomfort. ${ }^{34,36,37}$

The content of the virtual environment itself also seems to play a role in pain management. ${ }^{38}$ Distraction tasks need to be designed to vary the emotional significance and the personal relevance of the demand for attention. ${ }^{39}$ Graydon and Eysenck ${ }^{40}$ demonstrated an important distinction between difficulty and complexity of the chosen distraction task. The success of a distraction technique is also dependent on the task being sufficiently difficult to call upon resources otherwise allocated to pain. ${ }^{31}$ Eccleston and Crombez ${ }^{34}$ divided the factors implicated in moderating the interruption of the pain into two groups: factors related to pain (eg intensity, novelty, predictability and threat) and factors related to the demands of the environment (eg task difficulty and emotional arousal). A difficult task will consume most of the cognitive capacities and therefore make it difficult to perform successfully on other, unrelated tasks. ${ }^{31}$ With a higher cognitive load, the effort expended on a difficult task can consume attention, reducing the cognitive capacity to process painful stimuli. ${ }^{31}$

The aim of this study was to experimentally assess the relative importance of cognitive load and attentional focus on the analgesic effect of VR immersion during a cold pressor test (CPT). It was hypothesized that the virtual environment with the highest cognitive load would induce the most reduction in attention, and thus have the greatest analgesic effects in terms of increasing reports of pain tolerance and decreasing reports of pain intensity as assessed by VAS and questionnaire measures. ${ }^{31}$

\section{Methodology}

\section{Participants}

A convenience sample of 31 participants (20 women and 11 men) participated in the study. Ages ranged from 19 to 51 years, with a mean of $31(\mathrm{SD}=10.00)$. They were recruited through invitations distributed on the university campus and 
through the research assistants' Facebook accounts and contacts. Interested participants had to contact a research assistant who made first contact and determined eligibility. Participants were eligible if they were aged between 18 and 60 years old and willing to participate; participants were excluded if they were suffering from vestibular problems, epilepsy, migraines, hypertension, cardiovascular disease, if they were taking any pain medication (including over the counter pain medication), or if they reported any current medical condition. The research assistant used a checklist to determine if the participant met the inclusion/exclusion criteria, and excluded participants who tried to give a good impression by lasting more than 1.5 mins in the cold pressor test at the baseline or up to 5 mins during the experiment. This resulted in a final sample of 31 participants (see Table 1 for the number of participants per condition). This study was approved by the Universite du Québec en Outaouais's Research and Ethics Board (in accordance with the Declaration of Helsinki and Canadian rules for ethics in research). Written informed consent forms were obtained from all participants using a protocol approved by Université du Québec en Outaouais's Research and Ethics Board.

The study was initially designed to have four conditions (high and low cognitive load, focus of attention directed towards the hand immersed in cold water [nociceptive stimulus] or towards the foot [neutral stimulus]), with all conditions counterbalanced over four successive repeated VR immersions and cold pressor tests. However, after two experimental VR immersions, the cold pressor test displayed ceiling effects

Table I Mean (and Standard Deviation) for Age, Sex and Baseline Cold Pressor Test

\begin{tabular}{|l|l|l|l|}
\hline & Age & $\begin{array}{l}\text { Female } \\
\text { (\%) }\end{array}$ & $\begin{array}{l}\text { Baseline Cold Pressor } \\
\text { Duration (In Seconds) }\end{array}$ \\
\hline $\begin{array}{l}\text { Condition I: } \\
\text { High CL - FC } \\
(n=9)\end{array}$ & $\begin{array}{l}28.67 \\
(13.18)\end{array}$ & 44.4 & $35.50(10.24)$ \\
$\begin{array}{l}\text { Condition 2: } \\
\text { Low CL - FC } \\
(n=8)\end{array}$ & $\begin{array}{l}25.25 \\
(10.33)\end{array}$ & 75 & $38.44(17.85)$ \\
$\begin{array}{l}\text { Condition 3: } \\
\text { High CL - HC } \\
(n=7)\end{array}$ & $\begin{array}{l}(10.57 \\
\text { Condition 4: }\end{array}$ & 71.4 & $44.83(26.57)$ \\
$\begin{array}{l}\text { Low CL - HC } \\
(n=7)\end{array}$ & $(1.35)$ & 71.4 & 37.71 (10.64) \\
\hline
\end{tabular}

Abbreviations: $\mathrm{CL}$, cognitive load; $\mathrm{FC}$, video feed of the foot condition; $\mathrm{HC}$, video feed of the hand condition. and several extreme outlier data. ${ }^{41}$ Accordingly, the current study uses only the data from the first two experimental VR immersions, thus creating two experimental conditions where cognitive load either increased or decreased from VR Immersion 1 to VR Immersion 2, and where the focus of attention remained the same, changed toward the nociceptive stimuli, or changed away from the nociceptive stimuli (see Table 2). This design made it possible to test (a) whether an increase or decrease in cognitive load in VR had an impact on pain and (b) whether the impact on pain of a change in cognitive load was influenced by increasing or decreasing attention away from the nociceptive stimuli.

\section{Equipment and Measures Cold Pressor Apparatus}

The cold pressor apparatus used in this study was a commercial wine cooler designed to quickly chill a single bottle of wine (see Figure 1). This device provided a continuous circulation of cold water. A digital electric thermostat was placed in the water during the experimentation for accurate regulation of water temperature and flow. The water temperature was kept at $5 \circ \mathrm{C}$. Warmer temperatures have been reported to cause problems with ceiling effects as well as habituation. ${ }^{42}$

To protect participants from electric shocks due to wearing electrical equipment while in contact with water, each and every electric device used in the experiment was plugged into a GFA15-2C independent ground fault circuit interrupter from Leviton (15 amps, 120 volts, $60 \mathrm{~Hz}$ ). A stopwatch was used to monitor pain thresholds and pain tolerance times.

\section{VR Equipment}

The immersion was performed using a PC (running on Windows XP Pro with 4 GB of RAM and an NVIDIA GeForce 8800 GT video card), an immersive headmounted display (HMD) (nVisor SX60 from NVIS with a 60-degree diagonal field of view and a resolution of 1280

Table 2 Illustration of the Original Experimental Design for the First VR Immersion

\begin{tabular}{|l|l|l|l|}
\hline & \multicolumn{3}{|l|}{ Attentional Focus } \\
\hline \multirow{3}{*}{$\begin{array}{l}\text { Cognitive } \\
\text { load }\end{array}$} & High & $\begin{array}{l}\text { Away from } \\
\text { nociceptive stimuli } \\
\text { More flies, foot in the } \\
\text { visual field }\end{array}$ & $\begin{array}{l}\text { Toward nociceptive } \\
\text { stimuli } \\
\text { More flies, hand in the } \\
\text { visual field }\end{array}$ \\
\cline { 2 - 4 } & Low & $\begin{array}{l}\text { Fewer flies, foot in } \\
\text { the visual field }\end{array}$ & $\begin{array}{l}\text { Fewer flies, hand in } \\
\text { the visual field }\end{array}$ \\
\hline
\end{tabular}


A

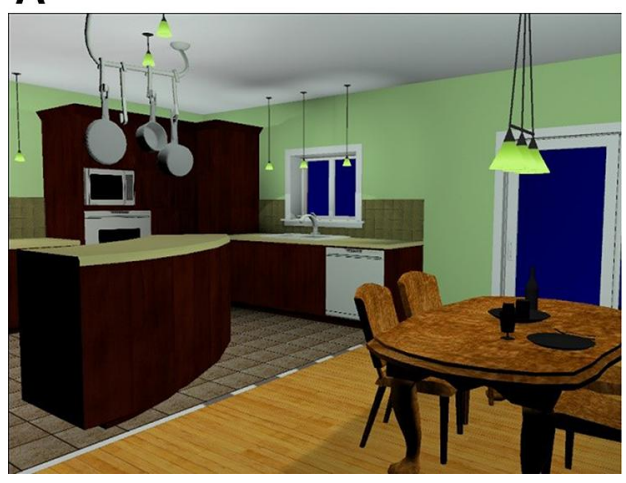

B

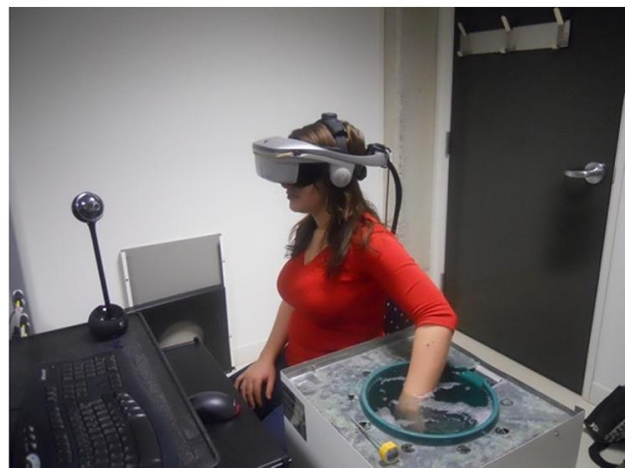

Figure I A screenshot of the virtual apartment (A) - left) and a person (B) - image reproduced with permission by written informed consent) immersed in the virtual environment with her non-dominant arm in the cold pressor. Note the webcam providing a live video feed of the immersed hand.

X 2014 pixels), a motion tracker attached to the HMD (360degree inertial Cube 2 from Intersence with a $180 \mathrm{~Hz}$ refresh rate), and a wireless mouse from Microsoft. The video feed was produced with a webcam (Logitech QuickCam Sphere AF) connected to the computer (see Figure 1-B). Head rotations allowed the participants to feel present in the environment and to aim at flies. Shooting was performed by clicking on the left mouse button. The virtual environment was a two-bedroom apartment. The immersion lasted 5 mins.

\section{VR Platform}

Participants were told they would visit a two-bedroom VR apartment while keeping their arm in the water for as long as they could (see Figure 1). The speed at which participants travelled through the apartment and direction in which they travelled was fixed and preprogrammed. Participants accordingly did not have to navigate in the apartment and could concentrate on the task. The research assistant informed each participant of their task, which was to kill as many flies as possible in the virtual environment. To kill flies, they had to use the target in the centre of their field of view, look at the flies and left-click on a mouse button to activate a trigger that would "kill" the flies.

The initial goal was to isolate cognitive load and focus of attention in a single virtual environment in which two variables were manipulated during each VR immersion.

\section{Cognitive Load}

Cognitive load was manipulated by having either more flies ( $\mathrm{n}=40$; High $\mathrm{CL}$ condition) or fewer flies $(\mathrm{n}=5$; Low CL condition) for participants to shoot at in the VE.

\section{Attentional Focus Condition}

Attentional focus was manipulated by presenting participants with either a live video feed of their hand immersed in the cold water (Hand Condition - HC, a reminder of the nociceptive stimuli; see Figure 2 for an illustration of the images displayed in the HMD, with the cold pressor in the field of view) or the participant's foot (Foot Condition - FC, stimuli irrelevant to the source of pain), also in the participants' field of view.

\section{Measures}

The primary outcome measure was pain tolerance, measured as the total length of time (seconds) participants left their hand immersed in cold water. We also measured pain intensity using a visual analog scale (VAS). The visual analog scale is a horizontal line $10 \mathrm{~cm}$ long with two endpoints labeled "no pain" and "worst pain ever". ${ }^{43}$ As soon as participants removed their hand from the water, they were required to mark the line at the point corresponding to the level of pain intensity they felt at the moment. ${ }^{44}$ The distance from the low end of the line to a participant's mark was used to determine the intensity of the pain. This type of scale is used in a variety of contexts in pain research and is useful

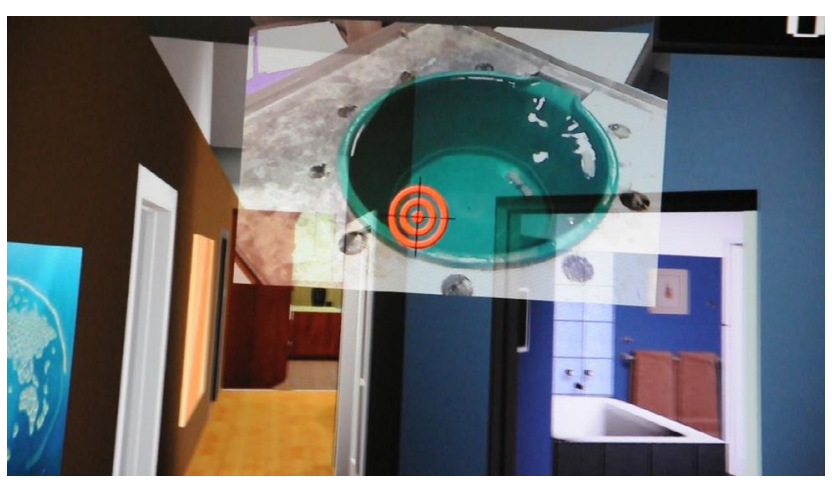

Figure 2 Viewpoint of the participant immersed in VR, with the live video feed from the cold pressor overlaid on the virtual apartment and the visual target. 
when the experimenter can observe behaviours associated with pain. ${ }^{43}$ The Short-Form McGill Pain Questionnaire $(\mathrm{SF}-\mathrm{MPQ})^{45}$ was also administered following each cold pressor trial. This brief questionnaire (5 mins) assesses the subjective pain experience, and scores with higher scores indicating acute pain conditions. ${ }^{44}$ Several studies have demonstrated its reliability (1 to 3-month test-retest reliability ranged from 0.45 to 0.73$),{ }^{46}$ construct validity $(r=0$.68-0.97 with pain scales of the SF-MPQ),${ }^{46}$ and internal consistency (Cronbach's alphas $=0.73-0.89) .{ }^{47}$ No psychometrics properties are available for healthy populations.

\section{Procedure}

Prior to the experiment, participants were advised not to take any prescription or over the counter pain medication. Upon arrival at the laboratory, participants were seated in a straight-back chair in an office lab maintained at a controlled temperature $\left(22^{\circ} \mathrm{C}\right)$. The research assistant then identified the non-dominant arm. Hand temperature was measured before the start of the procedure. The water temperature was monitored using a digital thermometer before and after each trial to ensure that it remained constant. A research assistant explained the purpose of the task with the following instructions: You will now proceed to the first cold pressor test to estimate your baseline level of pain tolerance. To do so, I will ask you to keep your arm, for as long as possible, in the cold-water tank. I will ask you to tell me the moment you will start feeling pain. Then, you can take your arm off the water tank when the pain is intolerable and you are under the impression that you cannot continue anymore. The immersion cannot last longer than 5 mins. Before the baseline assessments, the research assistant told participants that the water would be cold and that they might feel cold, numb or pain. The participants' non-dominant forearm was placed in 12 inches of cold water. Participants dried their arm with a warm blanket between each cold pressor test, and the hand was allowed to return to its initial temperature before the next test.

\section{Baseline and Familiarization}

As mention earlier, all participants underwent a baseline cold pressor trial during which their pain tolerance was measured (see Figure 3). No distraction was provided. Then, a training immersion in VR was performed without inducing any pain to allow participants to learn how to navigate in VR and manipulate the equipment.

\section{Statistical Analysis}

The dataset was examined to ensure that there was no outlier and statistical assumptions were met for the relevant analyses. One-way analyses of variance (ANOVA) were conducted to compare the four conditions (High CL - FC; Low CL - FC; High CL - HC; Low CL $\mathrm{HC}$ ) on variables such as age and baseline performance with the cold pressor test, and a chi-squared test was performed on the sex distribution between the conditions (see Table 1). For the main analyses, the data were analyzed with repeated-measures ANCOVAs with two Times (Immersion 1 and Immersion 2) and four Conditions (High CL - FC; Low CL - FC; High CL HC; Low CL - HC) (see Table 1) and the baseline score as a covariate. To correct for Type I error, a HolmBonferroni correction was applied to sequentially adjust the error level at 0.05 (which gives more power to the analyses than Bonferroni correction).

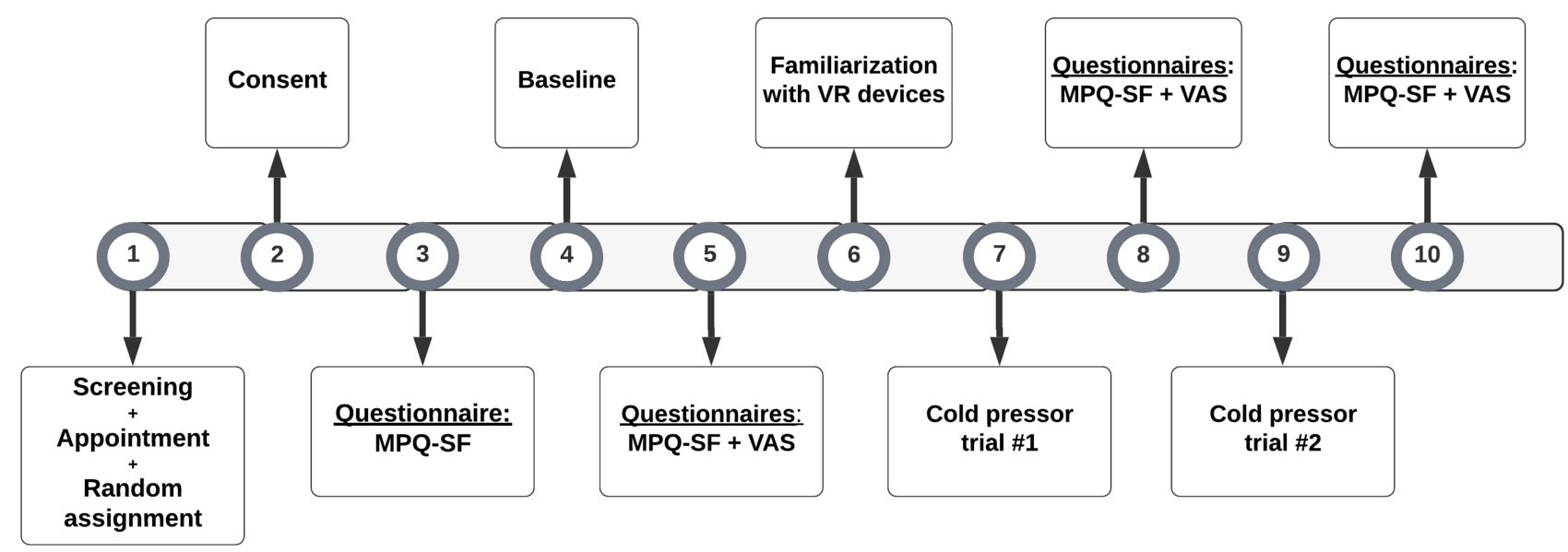

Figure 3 Flowchart of the procedure. 


\section{Results}

Comparisons between the conditions for potential differences in age, sex and baseline performance were not significant. The results of the analysis of the differential impact of cognitive load and attentional focus are reported in Tables 3 and 4. As presented in Table 4, the repeated-measures ANCOVA showed: (a) a significant effect compared to baseline for all three variables (pain tolerance, pain intensity and subjective pain measured with the MPQ); and (b) a significant Time $\mathrm{X}$ Condition interaction (illustrated in Figure 4) for the duration of hand immersion during the cold pressor task only (pain tolerance) after the experimental manipulations. The interaction for the tolerance on the cold pressor test was further examined with Time $\mathrm{X}$ Condition interaction contrasts, which revealed an effect of the VR immersion only in the conditions where there was an increase in cognitive load from VR Immersion 1 to VR Immersion 2 [contrast $\mathrm{F}(3,30)=7.635, \mathrm{p}<0.01$ ], without any impact from changing the focus away or toward the source of the nociceptive stimuli (see Figure 4).

\section{Discussion}

The aim of this study was to assess whether cognitive load and attentional focus are differentially associated with the analgesic effect of VR immersion during a cold pressor test. We hypothesized that immersions in VR would lead to an increase in pain tolerance during the cold pressor test and a decrease in pain intensity measured by the VAS and subjective pain measured by the SF-MPQ.

First, there was a significant effect from baseline on all measures of pain (increase in pain tolerance and decrease in pain intensity), replicating the results of previous studies on VR. Second, there was an effect of VR on the cold pressor test specific to the two conditions where there was
Table 3 Mean (and Standard Deviation) for the Pain Variables in Both Immersions, with Conditions Presented in Order of Increase or Decrease of Cognitive Load from the First to the Second Immersion in VR)

\begin{tabular}{|c|c|c|}
\hline & $\begin{array}{l}\text { VR } \\
\text { Immersion } \\
\text { I }\end{array}$ & $\begin{array}{l}\text { VR } \\
\text { Immersion } \\
2\end{array}$ \\
\hline $\begin{array}{l}\text { Pain tolerance (duration of the cold } \\
\text { pressor, in sec.) }\end{array}$ & & \\
\hline $\begin{array}{l}\text { Increase CL (Low } C L-F C \text { to } \\
\text { High } C L-H C)\end{array}$ & $46.75(27.23)$ & $64.38(37.28)$ \\
\hline $\begin{array}{l}\text { Increase } \mathrm{CL} \text { (Low } \mathrm{CL}-\mathrm{HC} \text { to } \\
\text { High } \mathrm{CL}-\mathrm{FC} \text { ) }\end{array}$ & $55.7 \mathrm{I}(29.5 \mathrm{I})$ & $68.57(33.16)$ \\
\hline $\begin{array}{l}\text { Decrease CL (High CL - FC to } \\
\text { Low } C L-F C)\end{array}$ & $48.67(19.81)$ & $53.22(26.93)$ \\
\hline $\begin{array}{l}\text { Decrease CL (High CL }-\mathrm{HC} \text { to } \\
\text { Low } \mathrm{CL}-\mathrm{HC})\end{array}$ & 55.71 (3I.95) & $49.86(29.88)$ \\
\hline Pain intensity (VAS) & & \\
\hline $\begin{array}{l}\text { Increase } C L \text { (Low } C L-F C \text { to } \\
\text { High } C L-H C)\end{array}$ & $63.5(26.42)$ & $71.13(27.8 I)$ \\
\hline $\begin{array}{l}\text { Increase } C L \text { (Low } C L-H C \text { to } \\
\text { High } C L-F C)\end{array}$ & $75.0(22.83)$ & $77.43(31.18)$ \\
\hline $\begin{array}{l}\text { Decrease } C L(H i g h C L-F C \text { to } \\
\text { Low } C L-F C)\end{array}$ & $88.67(16.2)$ & 87.11 (19.89) \\
\hline $\begin{array}{l}\text { Decrease CL (High } \mathrm{CL}-\mathrm{HC} \text { to } \\
\text { Low } \mathrm{CL}-\mathrm{HC})\end{array}$ & $84.0(16.86)$ & $83.57(17.23)$ \\
\hline $\begin{array}{l}\text { Subjective pain (SF-MPQ) } \\
\text { Increase CL (Low } C L-F C \text { to }\end{array}$ & $1825(15$ & $1838(16 \mid 8)$ \\
\hline $\mathrm{High} \mathrm{CL}-\mathrm{HC}$ ) & $10.20(15.17)$ & $10.30(10.10)$ \\
\hline $\begin{array}{l}\text { Increase } C L \text { (Low } C L-H C \text { to } \\
\text { High } C L-F C)\end{array}$ & I5.25 (6.26) & $17.14(9.97)$ \\
\hline $\begin{array}{l}\text { Decrease } C L(H i g h C L-F C \text { to } \\
\text { Low } C L-F C)\end{array}$ & $13.89(10.9)$ & $17.33(14.32)$ \\
\hline $\begin{array}{l}\text { Decrease } C L \text { (High } C L-H C \text { to } \\
\text { Low } C L-H C)\end{array}$ & $23.0(15.06)$ & $23.0(16.92)$ \\
\hline
\end{tabular}

Abbreviations: $\mathrm{CL}$, cognitive load; $\mathrm{FC}$, video feed of the foot condition; $\mathrm{HC}$, video feed of the hand condition; VAS, visual analog scale; SF-MPQ, Short Form-McGill Pain Questionnaire.

Table $4 \mathrm{~F}$ Values and Effect Sizes for the Repeated Measures ANCOVAs

\begin{tabular}{|c|c|c|c|c|c|}
\hline & \multicolumn{4}{|c|}{ F Values Tests for } & \multirow{2}{*}{$\begin{array}{l}\text { Partial Eta Squared for the } \\
\text { Interaction }\end{array}$} \\
\hline & $\begin{array}{l}\text { Baseline } \\
(\mathbf{d f}=I)\end{array}$ & $\begin{array}{l}\text { Time } \\
(\mathrm{df}=\mathrm{I})\end{array}$ & $\begin{array}{l}\text { Condition } \\
(\mathrm{df}=3)\end{array}$ & $\begin{array}{l}\text { Interaction } \\
(\mathrm{df}=3)\end{array}$ & \\
\hline $\begin{array}{l}\text { Pain tolerance (cold pressor duration, in } \\
\text { seconds) }\end{array}$ & $28.32 * * *$ & 0.003 & 0.77 & $3.47^{*}$ & 0.29 \\
\hline Pain intensity (VAS) & $25.74 * * *$ & 0.005 & 1.36 & 0.88 & 0.09 \\
\hline Subjective Pain (SF-MPQ) & $62.18 * * *$ & 0.66 & 0.42 & 0.99 & 0.10 \\
\hline
\end{tabular}

Note: $* \mathrm{p}<05, * * * \mathrm{p}<0.001$.

Abbreviations: VAS, visual analog scale; SF-MPQ, Short Form-McGill Pain Questionnaire. 


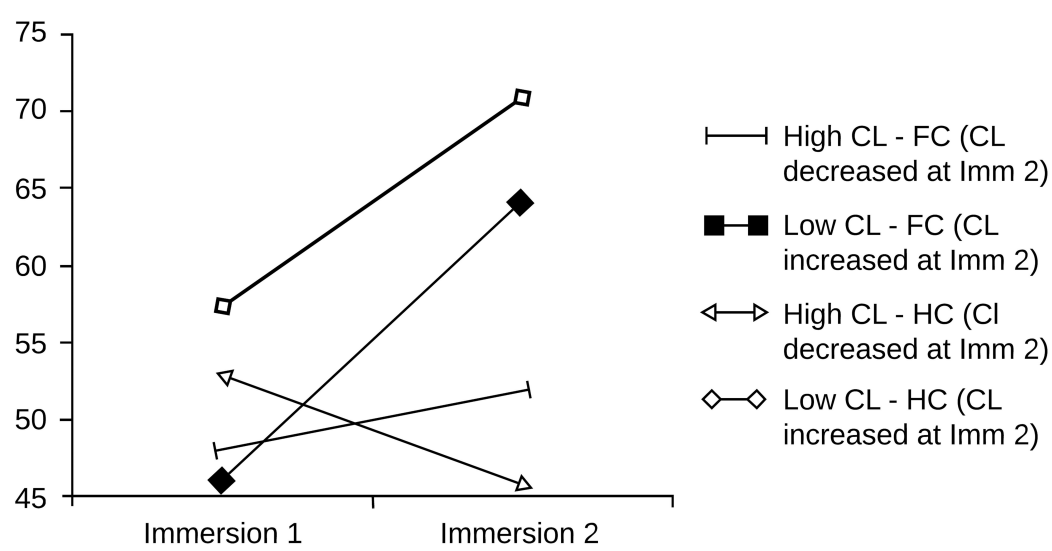

Figure 4 Visual illustration of the Time $X$ Conditions interaction for pain tolerance (duration of the cold pressor, in seconds) during the first and second immersion in virtual reality.

Abbreviations: $\mathrm{CL}$, cognitive load; FC, video feed of the foot condition; HC, video feed of the hand condition; Imm 2 , Immersion 2.

an increase in cognitive load from the first to the second immersion in VR. Being exposed to a video feedback of their hand did not differ from being exposed to a video feedback of their foot with regard to pain intensity ratings.

Indeed, the effect of attentional focus on the analgesic effect of VR was limited in this study. Even though we detected no difference attributable to attentional focus (hand vs foot), the results seem to underscore the role of cognitive load, a crucial element in the distracting effect. As our results show, when the cognitive load is reduced (ie fewer flies), the analgesic effect tends to be lost even if the focus of attention remains unchanged. Our results are consistent with the findings of Mühlberger et $\mathrm{al},{ }^{38}$ who conducted an experimental study on pain distraction and the effect of cold or warm virtual environments on cold or hot painful stimuli.

There are several possible explanations for why our hypotheses were only confirmed on one (pain tolerance on the cold pressor task) of the three variables. First, our cognitive load might not have been intense or high enough to have an impact on both pain tolerance and pain intensity. We designed a shooting game that has been previously shown to be sufficiently stimulating and engaging for participants. Some studies ${ }^{48}$ showed that interactive distraction is important to increase the analgesic effectiveness of VR. It is possible that our VR environment was built to be sufficiently interactive so the increase in cognitive load was sufficient to improve pain tolerance by $15 \mathrm{~s}$, but yet was not sufficiently stimulating or engaging to also lead to a significant decrease in pain intensity, as measured with the VAS and the questionnaire. Overall, the cognitive load created by the virtual environment may not have been high enough, in either situation (High CL and Low CL), and therefore only the change in cognitive load was significant.

Regarding our second hypothesis, several studies have suggested that attentional focus is a key concept in VR. ${ }^{22,49}$ Indeed, these studies demonstrated the power of adding an element of distraction when it comes to pain management. It is possible our manipulation of the focus of attention was not salient enough to influence participants. However, whether the content of the distractor is important or not remains an open question. Mühlberger et $\mathrm{al}^{38}$ showed that the type of virtual environment used for distraction has no effect on pain perception or management; both warm and cold virtual environments reduced pain for both heat and cold nociceptive stimuli compared to the control condition. Our results led us to a similar conclusion. Even though the content of the virtual environment was the same for all of the immersions, having a constant visual reminder of the nociceptive stimuli (ie hand in cold pressor apparatus) did not seem to affect pain tolerance ratings or have any impact on any other pain measure. Therefore, in our study, the main variable associated with better pain management seemed to be the cognitive load. Indeed, the more the virtual environment changed (ie number of flies or change from foot to hand in the visual field) between immersions, the more the participants' pain tolerance increased.

The two factors (cognitive load and attentional focus) also seem to emerge when looking at the results of literature reviews ${ }^{17,18}$ on VR as a distraction tool for pain management. Taking the focus of attention away from the painful stimuli is widely known to be effective when 
it comes to short-term pain management. That being said, it seems that distraction techniques requiring more attentional capacity (ie cognitive load) are considered more effective in pain management. ${ }^{31}$ Indeed, interactive distraction seems more effective at increasing pain tolerance and threshold than passive distraction, such as simply navigating through a virtual world. ${ }^{48,50}$ A difficult task is more likely to consume most of an individual's capacities, allowing fewer resources to attend to another unrelated task. $^{31}$ Other cognitive variables have been linked to cognitive load. Indeed, a study by Loreto-Quijada et $\mathrm{al}^{51}$ suggested that perceived control can significantly increase pain tolerance, pain sensitivity range, and self-efficacy in tolerating pain in participants in a cold pressor task compared to a control condition. An analysis by Triberti et $\mathrm{al}^{52}$ regarding the psychological factors influencing the effectiveness of VR analgesia revealed that the sense of presence (which can be modulated by cognitive load), fun, and emotions linked to the subjective experience of VR could influence the outcomes of interventions. However, most research cannot distinguish which strategy requires more attention capacity and, therefore, which one would be useful in the case of pain. This could warrant further studies.

\section{Limitations and Strengths}

There are several limitations of this study that warrant consideration. First, as mentioned earlier, although our virtual environment was created to be as stimulating and engaging as possible, the cognitive load created by the environment might have been too low. The environment should be improved in future studies by adding more stimuli or challenge, as appropriate for different age ranges. Second, due to problems associated with the repeated administration of the cold pressor test, only two VR immersions were examined in the study. This limits the possibility of comparing all pairing possibilities of high and low cognitive load with an attentional focus away or toward the nociceptive stimuli. Nevertheless, an examination of the two available VR immersions allowed us to draw some interesting preliminary conclusions. Third, the psychological factors influencing the effectiveness of virtual environment analgesia have only been partially explored in this study and some variables, like actual emotional experience (eg, distress ratings), were not assessed and might be worth measuring in future studies. Fourth, although VAS ratings are often obtained during the painful procedure, as in Mühlberger et $\mathrm{al}^{38}$ study our participants scored the VAS immediately after the cold pressor test. Otherwise, this would have influenced participants' attention during the immersion in VR. The location of the visual cue may also need to be reconsidered. It was placed in the visual field in such a way it would always remain visible during the immersion (ie, top and centered). In doing so, the visual cue was not cogently located where the participant experienced the pain from his or her hand (below the non-dominant corner of the visual field). Finally, it would be interesting in a future study to include a control group that would not have any of the two images overlaid into the virtual environment. That would control for the unknown impact of having a reminder of the physical reality included in the virtual reality, especially on presence.

Another limitation of this study is the potential selection bias and the representativeness of the convenience sample. The participants were recruited through invitations distributed around the university campus and through the research assistants' social network. Even though the research assistant did not know any of the participants, the final sample might not have been representative of the general population due to selection bias.

\section{Conclusion and Future Research}

This study aimed to assess the separate impact of cognitive load from attentional focus in the process of distraction from pain. Our results show that the increase in cognitive load from the first to the second immersion in VR led to an increase in pain tolerance, but being exposed to video feedback of their hand in cold water did not differ from being exposed to video feedback of their foot (not in cold water) with regard to pain ratings. Therefore, the effect of attentional focus on the analgesic effect of VR seems to be less important than cognitive load, which appears to be a crucial element in distracting from pain. Future studies should focus on cognitive load as their main variable when designing their virtual environment.

\section{Abbreviations}

CPT, Cold Pressor Test; HMD, head mounted display; SFMPQ, Short form McGill Pain Questionnaire; VAS, visual analog scale; VR, virtual reality.

\section{Data Sharing Statement}

The raw data supporting the conclusions of this manuscript will be made available by the authors, without undue reservation, to any qualified researcher. 


\section{Acknowledgments}

The authors wish to thank Noemie Bigras and Christine Beaudoin for their excellent technical assistance, the undergraduate students who participated in this study, and the IT team at UQO's Cyberpsychology Lab for their help with the development of the environment.

\section{Author Contributions}

All authors contributed to data analysis, drafting and revising the article, gave final approval of the version to be published, and agree to be accountable for all aspects of the work. The studies were conducted as part of the Ph.D. thesis of the first author, under the co-supervision of SB and KL.

\section{Funding}

The study was conducted thanks to the financial support obtained by the second author from the Canada Research Chairs (grant no. 950-10762).

\section{Disclosure}

Stéphane Bouchard is president and part-owner of In Virtuo, a company that distributes virtual environments, and conflict of interest is managed under UQO's conflict of interest policy. Kim L Lavoie reports personal fees from Boehringer Ingelheim and Abbvie, speaker honorarium; consulting fees related to the development of behavior change application for cancer patients from Astellas, speaker honorarium; consulting fees related to the development of behavior change application for asthma patients from Astra Zeneca, speaker honorarium; consulting fees related to the development of behavior change application for rheumatology patients from Janssen, speaker honorarium from Bayer and Novartis, and advisory boards for asthma for GSK, outside the submitted work. The authors report no other potential conflicts of interest for this work.

\section{References}

1. Janssen SA. Negative affect and sensitization to pain. Scand J Psychol. 2002;43(2):131-137. doi:10.1111/1467-9450.00278

2. Leventhal H, Brown D, Shacham S, Engquist G. Effects of preparatory information about sensations, threat of pain, and attention on cold pressor distress. J Pers Soc Psychol. 1979;37(5):688-714. doi:10.1037/0022-3514.37.5.688

3. Quartana PJ, Burns JW, Lofland KR. Attentional Strategy Moderates Effects of Pain Catastrophizing on Symptom-Specific Physiological Responses in Chronic Low Back Pain Patients. J Behav Med. 2007;30 (3):221-231. doi:10.1007/s10865-007-9101-z

4. Morley S, Eccleston C, Williams A. Systematic review and meta-analysis of randomized controlled trials of cognitive behaviour therapy and behaviour therapy for chronic pain in adults, excluding headache. Pain. 1999;80(1):1-13. doi:10.1016/s0304-3959(98)00255-3
5. Flor H. Psychological pain interventions and neurophysiology: implications for a mechanism-based approach. Am Psychol. 2014;69 (2):188-196. doi:10.1037/a0035254

6. Pascalis VD, Magurano MR, Bellusci A. Pain perception, somatosensory event-related potentials and skin conductance responses to painful stimuli in high, mid, and low hypnotizable subjects: effects of differential pain reduction strategies ì $^{2}$ Pain. 1999;83(3):499-508. doi:10.1016/s0304-3959(99)00157-8

7. Farthing GW, Venturino M, Brown SW, Lazar JD. Internal and External Distraction in the Control of Cold-pressor Pain as a Function of Hypnotizability. Int J Clin Exp Hypnosis. 1997;45 (4):433-446. doi:10.1080/00207149708416142

8. Patterson DR, Jensen MP. Hypnosis and clinical pain. Psychol Bull. 2003;129(4):495-521. doi:10.1037/0033-2909.129.4.495

9. Anderson RA, Baron R, Logan H. Distraction, Control, and Dental Stress1. J Appl Soc Psychol. 1991;21(2):156-171. doi:10.1111/ j.1559-1816.1991.tb00494.x

10. Fauerbach J, Lawrence J, Haythornthwaite J, Richter L. Coping with the stress of a painful medical procedure. Behav Res Ther. 2002;40 (9):1003-1015. doi:10.1016/s0005-7967(01)00079-1

11. Duker PC, Bercken JVD, Foekens M-A. Focusing versus distraction and the response to clinical electric shocks. J Behav Ther Exp Psychiatry. 1999;30(3):199-204. doi:10.1016/s0005-7916(99)00025-7

12. Fuchs P, Moreau G, Guitton P. Virtual Reality: Concepts and Technologies. Boca Raton, Fl: CRC Press; 2011.

13. Sadowski W, Stanney K. Presence in Virtual Environments. In: Stanney KM Editor. Handbook of Virtual Environments: Design, Implementation, and Applications. Mahwah, NJ, US: Lawrence Erlbaum Associates Publishers; 2002:791-806.

14. Hinds PS, Martin J. Hopefulness and the Self-Sustaining Process in Adolescents with Cancer. Nurs Res. 1988;37(6):6. doi:10.1097/ 00006199-198811000-00005

15. Sylvestre JC. A Process-Oriented Approach to the Study of Coping by Disengagement and Distraction. [Unedited Document]. Guelph: University of Guelph; 2000.

16. Schneider SM, Workman M. Effects of Virtual Reality on Symptom Distress in Children Receiving Chemotherapy. CyberPsychol Behav. 1999;2(2):125-134. doi:10.1089/cpb.1999.2.125

17. Dumoulin S, Bouchard S, Rivard V. Est-ce que la réalité virtuelle est un moyen efficace de gérer la douleur aiguë? Revue Québecoise de Psychologie. 2007;28(2):65-91.

18. Malloy KM, Milling LS. The effectiveness of virtual reality distraction for pain reduction: A systematic review. Clin Psychol Rev. 2010;30(8):1011-1018. doi:10.1016/j.cpr.2010.07.001

19. Sulea C, Soomro A, Boyd C, Wiederhold BK. Pain Management in Virtual Reality: A Comprehensive Research Chart. Cyberpsychol Behav Soc Netw. 2014;17(6):402-413. doi:10.1089/cyber.2014.1514

20. Mott J, Bucolo S, Cuttle L, et al. The efficacy of an augmented virtual reality system to alleviate pain in children undergoing burns dressing changes: A randomised controlled trial. Burns. 2008;34 (6):803-808. doi:10.1016/j.burns.2007.10.010

21. Das DA, Grimmer KA, Sparnon AL, Mcrae SE, Thomas BH. The efficacy of playing a virtual reality game in modulating pain for children with acute burn injuries: A randomized controlled trial [ISRCTN87413556]. BMC Pediatr. 2005;5(1):1. doi:10.1186/14712431-5-1

22. Hoffman HG, Doctor JN, Patterson DR, Carrougher GJ, Furness TA. Virtual reality as an adjunctive pain control during burn wound care in adolescent patients. Pain. 2000;85(1):305-309. doi:10.1016/ s0304-3959(99)00275-4

23. Sullivan C, Schneider PE, Musselman RJ, Dummett CO, Gardiner D. The effect of virtual reality during dental treatment on child anxiety and behavior. ASDC J Dent Child. 2000;67(3):193-196.

24. Gold JI, Kim SH, Kant AJ, Joseph MH, Rizzo A. Effectiveness of Virtual Reality for Pediatric Pain Distraction during IV Placement. CyberPsychol Behav. 2006;9(2):207-212. doi:10.1089/cpb.2006.9.207 
25. Gershon J, Zimand E, Lemos R, Rothbaum BO, Hodges L. Use of Virtual Reality as a Distractor for Painful Procedures in a Patient with Pediatric Cancer: A Case Study. CyberPsychol Behav. 2003;6 (6):657-661. doi:10.1089/109493103322725450

26. Gershon J, Zimand E, Pickering M, Rothbaum BO, Hodges L, Pilot A. Feasibility Study of Virtual Reality as a Distraction for Children With Cancer. J Am Acad Child Adolesc Psychiatry. 2004;43(10):1243-1249. doi:10.1097/01.chi.0000135621.23145.05

27. Wint SS, Eshelman D, Steele J, Guzzetta CE. Effects of Distraction Using Virtual Reality Glasses During Lumbar Punctures in Adolescents With Cancer. Oncol Nurs Forum. 2002;29(1):1. doi:10.1188/02.onf.e8-e15

28. Steele E, Grimmer K, Thomas B, Mulley B, Fulton I, Hoffman H. Virtual Reality as a Pediatric Pain Modulation Technique: A Case Study. CyberPsychol Behav. 2003;6(6):633-638. doi:10.1089/ 109493103322725405

29. Lee D, Chan A, Wong S, et al. Can Visual Distraction Decrease the Dose of Patient-Controlled Sedation Required During Colonoscopy? A Prospective Randomized Controlled Trial. Endoscopy. 2004;36 (03):197-201. doi:10.1055/s-2004-814247

30. Davis M, Vasterling J, Bransfield D, Burish TG. Behavioural interventions in coping with cancer-related pain. $B r J$ Guid Counc. 1987;15(1):17-28. doi:10.1080/03069888708251640

31. Mccaul KD, Malott JM. Distraction and coping with pain. Psychol Bull. 1984;95(3):516-533. doi:10.1037/0033-2909.95.3.516

32. Mccaffery M. Nursing approaches to nonpharmacological pain control. Int $J$ Nurs Stud. 1990;27(1):1-5. doi:10.1016/00207489(90)90018-e

33. Melzack R, Wall PD. The Challenge of Pain. New York: Basic Books; 1983.

34. Eccleston C, Crombez G. Pain demands attention: A cognitive-affective model of the interruptive function of pain. Psychol Bull. 1999;125(3):356-366. doi:10.1037/0033-2909.125.3.356

35. Price DD. Classical and current theories of pain mechanisms. In: Price DD, editor. Psychological and Neural Mechanisms of Pain. New York: Raven Press; 1988:212-231.

36. Villemure C, Bushnell CM. Cognitive modulation of pain: how do attention and emotion influence pain processing? Pain. 2002;95 (3):195-199. doi:10.1016/s0304-3959(02)00007-6

37. Farthing GW, Venturino M, Brown SW. Suggestion and distraction in the control of pain: test of two hypotheses. J Abnorm Psychol. 1984;93(3):266-276. doi:10.1037/0021-843x.93.3.266

38. Mühlberger A, Wieser MJ, Kenntner-Mabiala R, Pauli P, Wiederhold BK. Pain Modulation during Drives through Cold and Hot Virtual Environments. CyberPsychol Behav. 2007;10 (4):516-522. doi:10.1089/cpb.2007.9996

39. Maltzman S. Visual stimuli in distraction strategies for increasing pain tolerance: the confounding of affect with other stimulus characteristics. Pav J Bio Sci. 1988;23(2):67-74.
40. Graydon J, Eysenck MW. Distraction and cognitive performance. Eur J Cogn Psychol. 1989;1(2):161-179. doi:10.1080/ 09541448908403078

41. Dumoulin S, Loranger C, Gougeon V, Bouchard S, Lavoie KL Are cognitive load and focus of attention the main variables in pain management: an experimental study using a cold-pressor test and virtual reality. Poster presented at: 45th Annual Convention of the Association for Behavioral and Cognitive Therapy (ABCT); 2011; Toronto, ON.

42. Turk DC, Meichenbaum D, Genest M. Pain and Behavioral Medicine: A Cognitive-Behavioral Perspective. New York: The Guilford Press; 1983.

43. Jensen MP, Karoly P. Self-report scales and procedures for assessing pain in adults. In: Turk DC, Melzack R, editors. Handbook of Pain Assessment. New York: The Guilford Press; 2001:15-34.

44. Melzack R, Katz J. The McGill Pain Questionnaire: appraisal and current status. In: Turk DC, Melzack R, editors. Handbook of Pain Assessment. New York: The Guilford Press; 2001:35-52.

45. Melzack R. The short-form McGill pain questionnaire. Pain. 1987;30 (2):191-197. doi:10.1016/0304-3959(87)91074-8

46. Strand LI, Ljunggren AE, Bogen B, Ask T, Johnsen TB. The Short-Form McGill Pain Questionnaire as an outcome measure: test-retest reliability and responsiveness to change. Eur J Pain. 2008;12(7):917-925. doi:10.1016/j.ejpain.2007.12.013

47. Burckhardt CS, Bjelle A, Swedish A. Version of the Short-Form McGill Pain Questionnaire. Scand J Rheumatol. 1994;23(2):77-81. doi:10.3109/03009749409103032

48. Wender R, Hoffman HG, Hunner HH, Seiber EJ, Patterson DR, Sharar SR. Interactivity influences the magnitude of virtual reality analgesia. J Cyber Ther Rehabil. 2009;2(1):27-33.

49. Hoffman HG, Sharar SR, Coda B, et al. Manipulating presence influences the magnitude of virtual reality analgesia. Pain. 2004;111 (1):162-168. doi:10.1016/j.pain.2004.06.013

50. Dahlquist LM, Mckenna KD, Jones KK, Dillinger L, Weiss KE, Ackerman CS. Active and passive distraction using a head-mounted display helmet: effects on cold pressor pain in children. Health Psychol. 2007;26(6):794-801. doi:10.1037/0278-6133.26.6.794

51. Loreto-Quijada D, Gutiérrez-Maldonado J, Nieto R, et al. Differential Effects of Two Virtual Reality Interventions: distraction Versus Pain Control. Cyberpsychol Behav Soc Netw. 2014;17(6):353-358. doi:10.1089/cyber.2014.0057

52. Triberti S, Repetto C, Riva G. Psychological Factors Influencing the Effectiveness of Virtual Reality-Based Analgesia: A Systematic Review. Cyberpsychol Behav Soc Netw. 2014;17(6):335-345. doi:10.1089/cyber.2014.0054
Journal of Pain Research

\section{Publish your work in this journal}

The Journal of Pain Research is an international, peer reviewed, open access, online journal that welcomes laboratory and clinical findings in the fields of pain research and the prevention and management of pain. Original research, reviews, symposium reports, hypothesis formation and commentaries are all considered for publication. The manuscript management system is completely online and includes a very quick and fair peer-review system, which is all easy to use. Visit http:// www.dovepress.com/testimonials.php to read real quotes from published authors. 